\title{
Dealing with the Ups and Downs of Life: Positive Dispositions in Coping with Negative and Positive Events and Their Relationships with Well-Being Indicators
}

\author{
Giulia Fuochi ${ }^{1}$ (D) Alberto Voci ${ }^{1}$
}

Accepted: 12 October 2020 / Published online: 22 October 2020

(c) The Author(s) 2020

\begin{abstract}
In a four-wave, longitudinal study $(\mathrm{N}=323)$, we tested the relationships between five positive dispositions - mindfulness, self-compassion, gratitude, hedonism, and eudaimonism-and time-varying negative affect, positive affect, life satisfaction, and meaning in life. These relationships were tested while controlling for the ups and downs in life across three months, operationalized as the effects, for a respondent, of having experienced more frequent and intense positive and negative events compared to other individuals in the sample (inter-individual variation) and of having experienced more frequent and intense positive and negative events than usual for that person (intra-individual variation). We also tested the interactive effects between each disposition and intra-individual variation in the frequency and intensity of negative and positive events on well-being variables. Results, obtained through multilevel models with repeated observations nested in individuals, showed that each disposition had specific associations with well-being indicators, although stronger effects were detected for eudaimonism and, especially, self-compassion. Moderation analyses showed that: mindfulness and self-compassion buffered intra-individual variation in negative events; people scoring higher on hedonism, eudaimonism, and selfcompassion showed less need to rely on positive events to experience positive emotions; experiencing a negative event that was more intense than usual was associated with higher meaning in life for people with high levels of eudaimonism. Overall, findings suggest that mindfulness, self-compassion, gratitude, hedonism, and eudaimonism build well-being through different channels. Positive interventions could benefit from mixing these healthy functioning strategies and considering their roles in reactions to events.
\end{abstract}

Keywords Events $\cdot$ Well-being $\cdot$ Mindfulness $\cdot$ Self-compassion $\cdot$ Gratitude $\cdot$ Orientations to happiness $\cdot$ Hedonism $\cdot$ Eudaimonism $\cdot$ Coping

Giulia Fuochi

giulia.fuochi@unipd.it

1 Department FISPPA - Applied Psychology, Università degli Studi di Padova, Padua, Italy 


\section{Introduction}

Daily life is a constellation of minor stressors and positive happenings, and the extent to which events are able to affect our well-being hinges on how we deal with those ups and downs. People experiencing peaks of negative affect when daily stressors occur are more likely to report psychological symptoms or chronic health conditions a decade later, regardless of the number of stressors (Charles et al. 2013; Piazza et al. 2013). As for positive moments, it has been shown that sharing and intensely focusing on (savoring) positive events is related to higher momentary happiness (Jose et al. 2012). Highs and lows can also respectively catalyze post-ecstatic and post-traumatic growth, especially in terms of self-esteem, positive relations, and sense of mastery (Mangelsdorf et al. 2019); however, coping strategies, beliefs, and dispositions affect whether and how growth arises (Kashdan and Kane 2011). Importantly, highs and lows can be both represented as singular, self-relevant, impactful positive and negative events (Mangelsdorf et al. 2019), and as cumulated positive or cumulated negative events in a period, i.e., positive and negative events happening more than usual (Zautra et al. 2005). Indeed, both the intensity and the frequency of negative and positive events are related to psychological symptoms (Davis and Burns 1999).

Reactions to events are therefore a vital part of human functioning, and individual differences play a major role in the quality of such reactions. The aim of this paper is to investigate how five individual differences that might influence how people deal with events are associated with emotional and well-being reactions to the ups and downs of life. Besides contributing to the literature on well-being, understanding which dispositions may be able to counteract the emotional impact of negative events or to let the individual fully experience positive events can inform positive psychology interventions that aim to develop such dispositions, or that are based on theoretical frameworks linked to those dispositions. Indeed, the goal of positive interventions is to increase positive feelings, behaviors, and cognitions (Sin and Lyubomirsky 2009), and positive feelings in daily life hugely depend on naturally occurring events and on how people react to these events. A way to boost well-being is to increase the frequency-besides the intensity-of positive feelings and cognitions and to mitigate their decline in front of negative events, while reducing the potential increase in negative feelings. Thus, selecting a group of individual differences that are likely to be relevant in the management of daily negative and positive events and testing their buffering or facilitating effect in the relationship between such events and well-being can provide evidence on both their functionality in everyday life and their potential effectiveness in positive interventions.

Following these goals, we selected five positive dispositions and approaches to life - trait mindfulness, self-compassion, gratitude, hedonism, and eudaimonism-that showed to be: (1) related to higher levels of well-being (e.g., McCullough et al. 2002; Neff 2003; Peterson et al. 2005; Schueller and Seligman 2010; Weinstein et al. 2009); (2) characterized by different and functional strategies to cope with negative events (e.g., Dixon and Overall 2016; Fuochi et al. 2018a; Leary et al. 2007; Lambert et al. 2009); (3) potentially developed by specific interventions, or included in the foundations of positive interventions (Giannopoulos and Vella-Brodrick 2011; Neff and Germer 2013; Sin and Lyubomirsky 2009). We selected these five dispositions and not others with similar characteristics because each of them represents a side of optimal human functioning, involving specific cognitive processes and motivations: awareness of the present moment and of one's own inner states (mindfulness), a caring attitude toward 
the self (self-compassion), acknowledgment of and thankfulness for positive outcomes (gratitude), a quest for pleasure and positive feelings (hedonism), a quest for meaning in life (eudaimonism).

More specifically, trait mindfulness is defined as the tendency to remain focused on, and aware of, one's present-moment experience, with a nonjudgmental and accepting attitude (Kabat-Zinn 1994). Dispositional mindfulness buffers reactions to stressful situations (Brown and Ryan 2003; Weinstein et al. 2009), independently of emotion regulation, affect, and neuroticism (Dixon and Overall 2016). Highly mindful people regard daily events as less stressful (Weinstein et al. 2009), and in times of stress they aptly self-regulate (Brown and Ryan 2003), relying on approach-rather than avoidance-coping (Weinstein et al. 2009).

The second disposition we considered is self-compassion, defined as a gentle and healthy attitude toward one's failures and shortcomings, without engaging in self-indulgence (Neff 2003). Self-compassion is composed of three aspects: self-kindness, which is the tendency to avoid harsh self-judgment and to rely on kindness in front of one's own failures; mindfulness, which is a balanced awareness of personal negative experiences, without over-identifying with them; and common humanity, which is the belief that one's own limits and negative feelings are shared with the entire humanity. Besides being related to well-being, self-compassion was shown to buffer against both negative events and negative self-feelings (Leary et al. 2007), and it was positively associated with the belief that failures are learning opportunities and part of life (Miyagawa et al. 2019).

The third positive disposition was gratitude, defined as a tendency to acknowledge and appreciate the positive in the world, hence going far beyond the simple appreciation of other people's aid (McCullough et al. 2002; Wood et al. 2010). Besides involving thankfulness for lived positive circumstances and events, dispositional gratitude enables people to see negative events in a positive light, through positive reframing (Lambert et al. 2009). Moreover, a recent diary study showed that daily feelings of gratitude moderated relationships between stress and self-esteem, worry, depressogenic adjustment, and sadness (Nezlek et al. 2019).

As reactions to events may have different relationships with hedonic and eudaimonic well-being, especially for what concerns negative events (e.g., Charles et al. 2013; Kashdan and Kane 2011), we also considered hedonism and eudaimonism, respectively defined as a dispositional focus on pleasure (orientation to pleasure) and a dispositional focus on meaning and purpose (orientation to meaning) in people's route to happiness (Huta and Waterman 2014). Both hedonism and eudaimonism were shown to be positively associated with life satisfaction and positive affect, and negatively associated with negative affect, with slightly stronger relationships for eudaimonism (Schueller and Seligman 2010).

Eudaimonism was found to buffer the effect of stressful events on well-being (Fuochi et al. 2018a); moreover, when remembering a recent negative event, people scoring higher on hedonism felt more high-arousal positive affect, while people scoring higher on eudaimonism were more likely to experience low-arousal positive affect (Fuochi et al. 2018a). Thus, hedonism and eudaimonism may both help individuals cope with events, but through different channels. The pursuit of pleasurable experiences (hedonism) may help people focus on the positive, while the pursuit of self-realization (eudaimonism) may help people make sense out of negative experiences, thereby finding meaning (Huta and Waterman 2014).

These five dispositions have been part of many interventions: mindfulness is the core of Mindfulness-Based Stress Reduction (Kabat-Zinn 1990) and Mindfulness-Based Cognitive Therapy (MBCT; Teasdale et al. 2000), and is part of several positive psychology 
interventions (Sin and Lyubomirsky 2009). Self-compassion is the theoretical foundation of the Mindful Self-compassion Program (Neff and Germer 2013) and of other self-compassion interventions (e.g., Smeets et al. 2014). Positive psychology interventions about and involving gratitude are many (for a review, see Sin and Lyubomirsky 2009). Hedonism and eudaimonism have been included in interventions based on the Orientations to Happiness (OTH) framework (Peterson et al. 2005), with positive results on well-being, also in the long run (Gander et al. 2016; Giannopoulos and Vella-Brodrick 2011). Most of these five dispositions have also been part of smartphone-based interventions (e.g., Howells et al. 2016) and of multi-component positive psychology interventions (Hendriks et al. 2019), such as the Positive Mindfulness Program (Ivtzan et al. 2016), which included mindfulness, self-compassion, gratitude, self-efficacy, together with other positive dispositions and emotions.

Interestingly, despite some evidence on the relationships between these five dispositions and reactions to stressful events-mostly uncovering buffering roles toward negative events -, their associations with emotional and well-being reactions to positive events have never been studied. Moreover, evidence is lacking on how these dispositions are associated with reactions to an increasing intensity and frequency of events, specifically. Lastly, past research did not often consider intra-individual dynamics in well-being and reactions to events, providing, in most cases, a quite static picture of the relationship between wellbeing and positive dispositions. The present research aimed to address these gaps in the literature.

\section{Aims and Hypotheses}

This study aimed to investigate the roles of five positive dispositions related to well-being and to coping with stress, and potentially developed by or included in positive interventions, in individuals' reactions to the ups and downs of life. In particular, we aimed to test the extent to which mindfulness, self-compassion, gratitude, hedonism, and eudaimonism are associated with healthier emotional and well-being dynamics following negative and positive events.

In a four-wave, longitudinal study, with a four-week interval between the waves, we asked participants to report, with reference to the preceding four weeks, the frequency of negative and positive events occurred to them, together with the intensity of the most impactful self-relevant negative event and of the most impactful self-relevant positive event. Then, we separated between-individual from within-individual variation in the frequency and intensity of negative and positive events. To do this, we computed the person means (Level-2, time-invariant variables) of event variables, which are the person's average levels of frequency and intensity of negative and positive events, and the person-mean centered scores of such event variables, obtained by subtracting the respective person mean from the person's score of the respective variable, as reported in each wave (Level-1, timevarying variables). The person mean is the between-individual—or inter-individual-variation, while person-mean centered scores are within-individual—or intra-individual—variation. In multilevel models, the effect of the person mean of - for instance-the frequency of events represents the effect of experiencing more events than other individuals, whereas the effect of the person-mean centered frequency of events represents the effect of experiencing more events than usual for a person (e.g., Hoffman and Stawski 2009). 
This procedure has two important advantages: first, as people may be used to-or used to perceive - a certain number and a certain intensity level of negative and positive events (Zautra et al. 2005), distinguishing between-person from within-person effects allows us to control for both the "contextual effect" of living a life generally characterized by multiple or more intense events, and person-specific tendencies in evaluating the frequency and intensity of events (e.g., Hoffman and Stawski 2009), thus allowing us to identify pure within-individual variation. Second, interacting each disposition first with the intra-individual variation in the frequency of negative and positive events, and then with the intraindividual variation in the intensity of the most impactful recent negative event and of the most impactful recent positive event, allows us to investigate the role played by positive dispositions in well-being changes when negative and positive events are more frequent and more intense than usual for a person.

In sum, by conducting multilevel models with time-repeated measurements nested within individuals, we tested: (a) the associations that each disposition-mindfulness, selfcompassion, gratitude, hedonism, and eudaimonism-has with aspects of (time-varying) subjective and eudaimonic well-being, in particular positive and negative affect, life satisfaction, and meaning in life, while controlling for between-individual and within-individual variation in events, and the other dispositions; (b) the interactive effects between each of these five dispositions and intra-individual variation in the frequency and intensity of negative and positive events on well-being variables.

Based on previous evidence on the relationships between the considered dispositions and well-being dimensions (e.g., McCullough et al. 2002; Neff 2003; Peterson et al. 2005; Weinstein et al. 2009), we hypothesized that our five dispositions would be negatively associated with time-varying negative affect, and positively associated with time-varying positive affect, life satisfaction, and presence of meaning in life (H1). Consistent with past research on the buffering effects of dispositional mindfulness and self-compassion on stressful events (Dixon and Overall 2016; Leary et al. 2007; Weinstein et al. 2009), we hypothesized that reactions to the intra-individual variation in the frequency and intensity of negative events would be buffered by both mindfulness (H2) and self-compassion (H3). Consistent with the buffering effect of gratitude on stress found in past research (Nezlek et al. 2019) and with the definition of gratitude as appreciation of the positive aspects in life (Wood et al. 2010), we hypothesized that gratitude would be associated with stronger positive well-being reactions to positive events, but also with mitigated reactions to negative events (H4). In particular, as gratitude involves the tendency to acknowledge personal positive situations, individuals with higher levels of gratitude may be more able to savor positive events (Jose et al. 2012), thereby experiencing a stronger positive link between positive events and well-being (H4). Based on the OTH framework, and consistent with past research showing that hedonism and eudaimonism help feeling positive emotions when recalling a negative event (Fuochi et al. 2018a), we hypothesized that they would both interact with the relationship between intra-individual variation in negative events and well-being (H5).

\section{Method}

The procedures of this study were approved by the Psychological Research Ethics Committee of the University of Padova, protocol number 1990. 


\subsection{Participants}

Participants, who were recruited by psychology master students in return for a courserelated bonus, completed online questionnaires. Each student identified four individuals (when possible, two men and two women) who met three requirements: they were willing to participate in a longitudinal, 12-week study, they were not students in the course, and they did not know each other-to decrease dependence among observations. The questionnaire included all the variables (dispositions, event questions, well-being variables) in the first wave, and only time-varying variables (event questions, well-being variables) in the subsequent three waves; the time interval between waves was four weeks.

The sample size was 356 in the first wave, 329 in the second one, 312 in the third one, and 305 in the fourth one. As three repeated measures for each participant are necessary for a proper longitudinal study (Ployhart and Vandenberg 2010), and as we wanted to compute reliable intra-individual variation in negative and positive events, we kept in the sample only respondents who completed the questionnaire at least three times including the first wave $(\mathrm{N}=323)$. This also provided us with a sufficient number of within-cluster units for multilevel models (Snijders 2005). Attrition was handled by multilevel analyses, which do not require the same number of individuals at each time point.

All participants in the sample $(\mathrm{N}=323,52 \%$ women $)$ were Italian, and age ranged from 18 to 67 years $(M=27.52 ; S D=10.87)$. The highest education level achieved was secondary school for $4 \%$ of the sample, high school diploma for $48 \%$ of the sample, bachelor's degree for $33 \%$ of the sample, and higher degrees (master's, Ph.D.) for $15 \%$ of the sample. As for participants' occupations, $60 \%$ were students; $18 \%$ were retailers, employees, or teachers in primary schools; $8 \%$ were manual workers; $7 \%$ were professionals, high school teachers, or university professors; the rest were unemployed or did not report any occupation.

\subsection{Measures}

\subsubsection{Mindfulness}

Dispositional present-moment awareness was measured with the validated Italian version of the 15-item Mindful Attention Awareness Scale (MAAS; Brown and Ryan 2003; Veneziani and Voci 2015; example item, reverse-scored: "I find it difficult to stay focused on what is happening in the present"). Respondents answered on a 7-point scale, from 1 (almost never) to 7 (almost always). Higher scores, after appropriate reverse-coding, indicated higher levels of trait mindfulness, in particular in its aspects of attention to inner and outer experience and awareness of the present moment $(\alpha=0.87)$.

\subsubsection{Self-compassion}

Self-compassion was measured with the short form (12 items) of the Self-Compassion Scale (SCS-SF; Raes et al. 2011; example item: "I try to be understanding and patient towards those aspects of my personality I don't like"). Italian items were retrieved from the validated longer version of the scale (Veneziani et al. 2017). The scale measures the tendency to be kind toward the self in times of trouble, and to see personal failings in a 
balanced way, recognizing them as part of the human experience. Respondents answered on a 5-point scale, from 1 (almost never) to 5 (almost always). Higher overall scores indicated higher levels of self-compassion $(\alpha=0.80)$.

\subsubsection{Gratitude}

The validated Italian version of the 6-item Gratitude Questionnaire (GQ-6; McCullough et al. 2002; Fuochi et al. 2018b; example item: "I have so much in life to be thankful for"), with items on a 5-point agreement scale (from $1=$ strongly disagree to $5=$ strongly agree), was employed to assess individual differences in the proneness to experience gratitude $(\alpha=0.78)$.

\subsubsection{Hedonism and eudaimonism}

Hedonism and eudaimonism were measured respectively with the orientation to pleasure ( $\alpha=0.75$; example item: "Life is too short to postpone the pleasures it can provide") and to meaning ( $\alpha=0.70$; example item: "My life serves a higher purpose") subscales (6 items each) of the OTH scale (Peterson et al. 2005; Italian validated version by Fuochi et al. 2018a), which respectively represent the view of life as a search for pleasure and as a search for meaning. Respondents answered on a 5-point scale, from 1 (very much unlike me) to 5 (very much like me).

\subsubsection{Frequency and intensity of negative and positive events}

The frequency of negative and positive events in the preceding four weeks and the intensity of the most impactful and self-relevant negative event and positive event occurred in the preceding four weeks were measured with single-item questions in each of the four waves. Participants were told "Sometimes negative events occur, more or less unexpected. Think about the last four weeks while you answer the following question: How much do you feel that the last few weeks have been marked by negative events (for instance, health issues involving you or people close to you, changes, difficulties at work)?", answering the question on a scale from 1 (not at all) to 7 (a great deal). As the time span between waves could be slightly different from four weeks because participants had almost one week to access the link of the online questionnaire, in waves 2,3 , and 4, we specified "Think about the last four weeks, and in particular about the time passed since the last time you filled in this questionnaire...". After the question on the frequency of negative events in the preceding four weeks, participants were asked to recall the most impactful, self-relevant recent negative event - the one with "the strongest impact on you and your mood"-occurred in the preceding four weeks. To assess the perceived intensity of this self-relevant negative event, respondents rated how negative this event was from 1 (minimum negativity) to 10 (maximum negativity). Immediately after these questions about negative events, the questions were repeated, with corresponding instructions, for positive events occurred in the last few weeks and for the most impactful, self-relevant recent positive event. The order of negative and positive events was not counterbalanced among respondents.

For each event question we computed the Intraclass Correlation Coefficient (ICC, i.e. the proportion of between-person variance in the total amount of within- and betweenvariance). Between-person variance, compared to total variance, was low for all event variables (ICCs from 0.23 to 0.29 ), suggesting substantial intra-individual variation in 
frequency and intensity of negative and positive events. As previously mentioned, for each event question we computed the person mean and person-mean centered scores, to respectively assess between-person variation and within-person variation of events.

\subsubsection{Positive and Negative Emotions}

We assessed positive and negative affect felt in the preceding four weeks with the Italian version (Terracciano et al. 2003) of the 20-item Positive and Negative Affect Schedule (PANAS; Watson et al. 1988). Respondents answered on a scale from 1 (not at all) to 5 (very much). Both negative and positive affect were reliable in all waves ( $\alpha \mathrm{s}=0.87-0.90$ for both negative and positive affect), and the variability of negative ( ICC $=0.58$ ) and positive affect $(\mathrm{ICC}=0.55)$ was almost equally due to between-person and within-person variations.

\subsubsection{Life Satisfaction}

We employed the Italian version of the 5-item Satisfaction with Life scale (SWLS; Diener et al. 1985; example item: "I am satisfied with my life"); respondents answered on a 7-point agreement scale. The SWLS was reliable in all waves $(\alpha s=0.89-0.90)$, and the variability was mostly inter-individual (ICC $=0.75$ ).

\subsubsection{Meaning in Life}

The 5-item Presence of Meaning subscale of the Meaning in Life Questionnaire (MLQ; Steger et al. 2006; example item: "My life has a clear sense of purpose") was employed to assess perceived meaning and purpose in life; respondents answered the items on a response scale from 1 (completely false) to 7 (completely true). Presence of meaning was reliable in all waves ( $\alpha \mathrm{s}=0.84-0.87)$, and the variability was mostly inter-individual $(\mathrm{ICC}=0.76)$.

\section{Results}

First, we computed descriptive statistics of the variables of the study, namely means, standard deviations, and Pearson correlations between the variables (Table 1); for what concerns time-varying variables (events, well-being), correlations were calculated on their person means. All five dispositions were positively and significantly correlated among themselves, with slightly stronger correlations $(r>0.30)$ between mindfulness and self-compassion $(r=0.33)$, self-compassion and gratitude $(r=0.34)$, and gratitude and eudaimonism $(r=0.34)$.

To test our hypotheses, we employed multilevel models with repeated observations nested within individuals. As recommended for data with unplanned trends (Wang and Maxwell 2015), in all the models we controlled for time in a categorical form (three dichotomous variables for waves 2,3 , and 4 , taking value 1 in the related wave and 0 otherwise, with the first wave as reference category), because exploratory analyses showed that emotions variables and the intensity of the positive event exhibited initial elevation and a nonlinear downward trend, as frequently found in longitudinal data (Shrout et al. 2018). Based on model fit and parsimony criteria (Gurka 2006), we performed random-intercept multilevel models, which provided a best fit (a lower BIC) compared to random-slope, random 


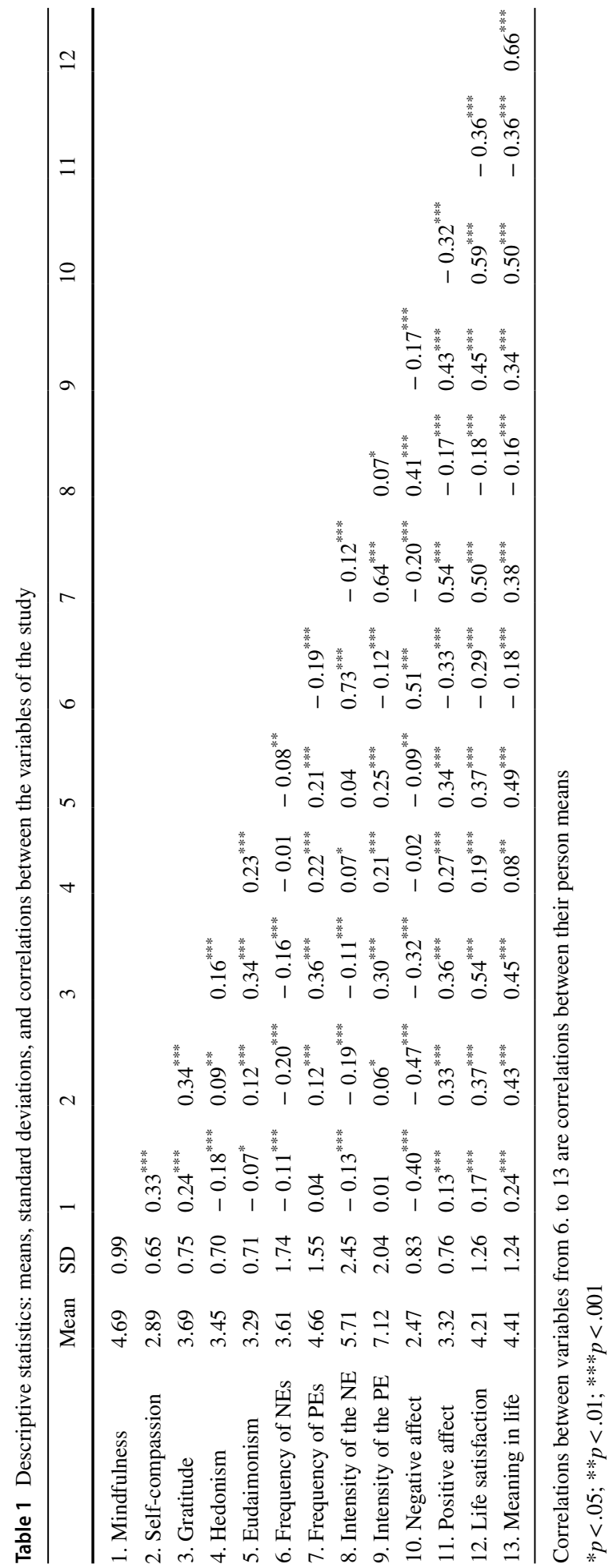


intercept models. P-values were derived with Kenward-Roger approximation while using REML, as recommended to achieve the smallest Type 1 error rates in linear mixed models (Luke 2017). We employed the R (R Core Team 2019) packages lme4 (Bates at al. 2015) and sjPlot (Lüdecke 2020).

\subsection{Multilevel Analysis of the Associations Between Positive Dispositions and Time-Varying Well-Being}

To test H1, each well-being variable was first modeled as a function of the five dispositions, between-individual and within-individual variation in the frequency of negative and of positive events, age, gender, and time; results are reported in Table 2. Second, the same models were repeated for the intensity of events: between-individual and within-individual variation in the intensity of the self-relevant negative and the self-relevant positive event mentioned in each wave substituted the respective variables for events frequency (see Table 3).

Results reported in Table 2 showed that both between- and within-individual variation in the frequency of negative events were positively associated with negative affect, negatively associated with positive affect, and unrelated to meaning in life. This lack of

Table 2 Multilevel analysis of the associations between positive dispositions and time-varying well-being, controlling for between- and within-individual variation in the frequency of events

\begin{tabular}{|c|c|c|c|c|c|c|c|c|}
\hline & \multicolumn{2}{|c|}{ Negative affect } & \multicolumn{2}{|c|}{ Positive affect } & \multicolumn{2}{|c|}{ Life satisfaction } & \multicolumn{2}{|c|}{ Meaning in life } \\
\hline & $\mathrm{b}$ & $p$ & $\mathrm{~b}$ & $p$ & $\mathrm{~b}$ & $p$ & $\mathrm{~b}$ & $p$ \\
\hline Intercept & 4.01 & $<.001$ & 1.10 & $<.001$ & -0.72 & .133 & -1.21 & .013 \\
\hline Age & -0.01 & $<.001$ & 0.00 & .564 & -0.00 & .353 & 0.01 & .004 \\
\hline Gender & 0.10 & .082 & -0.08 & .163 & -0.04 & .676 & 0.11 & .260 \\
\hline Wave 2 & -0.09 & .037 & -0.13 & .001 & 0.21 & $<.001$ & 0.03 & .532 \\
\hline Wave 3 & -0.06 & .163 & -0.21 & $<.001$ & 0.23 & $<.001$ & 0.06 & .196 \\
\hline Wave 4 & -0.14 & .001 & -0.24 & $<.001$ & 0.21 & $<.001$ & 0.13 & .007 \\
\hline B-P frequency of NEs & 0.23 & $<.001$ & -0.10 & $<.001$ & -0.12 & .004 & -0.06 & .156 \\
\hline B-P frequency of PEs & -0.04 & .152 & 0.24 & $<.001$ & 0.33 & $<.001$ & 0.24 & $<.001$ \\
\hline W-P frequency of NEs & 0.11 & $<.001$ & -0.04 & $<.001$ & -0.03 & .089 & -0.00 & .974 \\
\hline W-P frequency of PEs & -0.05 & $<.001$ & 0.11 & $<.001$ & 0.05 & .001 & 0.06 & $<.001$ \\
\hline Mindfulness & -0.17 & $<.001$ & 0.04 & .214 & 0.04 & .460 & 0.12 & .029 \\
\hline Self-compassion & -0.26 & $<.001$ & 0.17 & $<.001$ & 0.33 & $<.001$ & 0.46 & $<.001$ \\
\hline Gratitude & -0.08 & .083 & 0.02 & .574 & 0.43 & $<.001$ & 0.17 & .023 \\
\hline Hedonism & -0.03 & .473 & 0.11 & .006 & 0.03 & .702 & -0.11 & .132 \\
\hline Eudaimonism & 0.00 & .913 & 0.17 & $<.001$ & 0.30 & $<.001$ & 0.60 & $<.001$ \\
\hline Observations & 1191 & & 1191 & & 1189 & & 1190 & \\
\hline Within-person variance & 0.25 & & 0.22 & & 0.39 & & 0.35 & \\
\hline Between-person variance & 0.17 & & 0.15 & & 0.57 & & 0.59 & \\
\hline Conditional $\mathrm{R}^{2}$ & .633 & & 620 & & .760 & & .777 & \\
\hline
\end{tabular}

$B$ - $P$ Between-person, $W-P$ Within-person, $N E s$ negative events, $P E s$ positive events

$P$-values derived with Kenward-Roger approximation, while using REML. Within-person variance is the variance of the error term at Level 1, namely the residual variance; between-person variance is the variance of the random intercept 
Table 3 Multilevel analysis of the associations between positive dispositions and time-varying well-being, controlling for between- and within-individual variation in the intensity of events

\begin{tabular}{|c|c|c|c|c|c|c|c|c|}
\hline & \multicolumn{2}{|c|}{ Negative affect } & \multicolumn{2}{|c|}{ Positive affect } & \multicolumn{2}{|c|}{ Life satisfaction } & \multicolumn{2}{|c|}{ Meaning in life } \\
\hline & $\mathrm{b}$ & $p$ & $\mathrm{~b}$ & $p$ & $\mathrm{~b}$ & $p$ & $\mathrm{~b}$ & $p$ \\
\hline Intercept & 4.49 & $<.001$ & 1.02 & $<.001$ & -0.89 & .065 & -1.17 & .013 \\
\hline Age & -0.01 & $<.001$ & -0.00 & .993 & -0.00 & .426 & 0.01 & .002 \\
\hline Gender & 0.13 & .032 & -0.07 & .244 & -0.01 & .892 & 0.15 & .113 \\
\hline Wave 2 & -0.09 & .046 & -0.15 & $<.001$ & 0.21 & $<.001$ & 0.01 & .851 \\
\hline Wave 3 & -0.06 & .151 & -0.20 & $<.001$ & 0.26 & $<.001$ & 0.07 & .149 \\
\hline Wave 4 & -0.13 & .004 & -0.24 & $<.001$ & 0.24 & $<.001$ & 0.13 & .009 \\
\hline B-P intensity of the NE & 0.13 & $<.001$ & -0.05 & .002 & -0.09 & .002 & -0.08 & .006 \\
\hline B-P intensity of the PE & -0.07 & .001 & 0.15 & $<.001$ & 0.24 & $<.001$ & 0.17 & $<.001$ \\
\hline W-P intensity of the NE & 0.06 & $<.001$ & -0.02 & .008 & -0.01 & .523 & 0.01 & .186 \\
\hline W-P intensity of the PE & -0.03 & .007 & 0.06 & $<.001$ & 0.04 & $<.001$ & 0.04 & $<.001$ \\
\hline Mindfulness & -0.17 & $<.001$ & 0.05 & .120 & 0.03 & .514 & 0.11 & .043 \\
\hline Self-compassion & -0.29 & $<.001$ & 0.16 & .001 & 0.33 & $<.001$ & 0.46 & $<.001$ \\
\hline Gratitude & -0.08 & .090 & 0.06 & .197 & 0.46 & $<.001$ & 0.21 & .005 \\
\hline Hedonism & -0.04 & .403 & 0.11 & .008 & 0.04 & .615 & -0.11 & .112 \\
\hline Eudaimonism & -0.01 & .765 & 0.15 & .001 & 0.27 & $<.001$ & 0.57 & $<.001$ \\
\hline Observations & 1159 & & 1159 & & 1156 & & 1158 & \\
\hline Within-person variance & 0.26 & & 0.23 & & 0.39 & & 0.35 & \\
\hline Between-person variance & 0.20 & & 0.18 & & 0.58 & & 0.57 & \\
\hline Conditional $\mathrm{R}^{2}$ & .621 & & .586 & & .749 & & .775 & \\
\hline
\end{tabular}

$B$ - $P$ Between-person, $W-P$ Within-person, $N E$ most impactful negative events, $P E$ most impactful positive events

$P$-values derived with Kenward-Roger approximation, while using REML. Within-person variance is the variance of the error term at Level 1, namely the residual variance; between-person variance is the variance of the random intercept

relationship may signal that some negative events are negatively related to eudaimonia, while others may be positively related to this aspect of well-being, consistent with past research showing that people find meaning in negative events (Baumeister et al. 2013). Between-person-but not within-person - variation in the frequency of negative events was also negatively associated with life satisfaction; the lack of association with withinperson variation may be explained with the lower fluctuations of satisfaction with life $(\mathrm{ICC}=0.75)$. Both between- and within-individual variation in the frequency of positive events were related to higher well-being; for what concerns negative affect and frequent positive events, only within-person variation mattered.

Results were somewhat similar for the intensity of the most impactful self-relevant recent negative event and positive event (Table 3). Between-individual variation in the intensity of the selected negative event was positively associated with negative affect, and negatively associated with positive affect, life satisfaction, and meaning in life. Withinindividual variation in the intensity of the negative event was instead associated only with emotions, consistent with what found for within-person variation in the frequency of negative events, suggesting that experiencing a more stressful period or event than usual has stronger effect on well-being indicators that fluctuate more, such as emotions (ICCs $=0.55$, 
0.58), compared to more stable forms of well-being, such as life satisfaction (ICC $=0.75$ ). Between- and within-person variation in the intensity of the selected positive event were instead associated with all types of well-being, i.e., emotions, life satisfaction, and meaning. Taken together, these results suggest that negative and positive events have both a contextual and a situational effect: both experiencing more frequent or more intense events than other people and experiencing more frequent or more intense events than usual for a person have an association with well-being, although intra-individual fluctuations in negative events were related only to affective outcomes.

Looking at the role of individual dispositions, we found that both when controlling for the frequency (Table 2) and the intensity (Table 3) of negative and positive events, and for all other dispositions, mindfulness was negatively associated with negative affect and positively associated with meaning in life, whereas self-compassion was negatively related to negative affect and positively related to all other forms of well-being. In the same models, gratitude was positively associated with life satisfaction and meaning in life but not with positive and negative affect, while hedonism and eudaimonism were positively associated with positive affect, and eudaimonism was also positively related to life satisfaction and meaning in life.

These results showed that, once controlling for the intercorrelations amongst the five positive dispositions, different aspects of well-being were related to different dispositions. Negative affect was negatively associated with mindfulness and self-compassion, whereas positive affect was positively related to self-compassion, hedonism, and eudaimonism. Satisfaction with life was positively associated with self-compassion, gratitude, and eudaimonism. Finally, meaning in life was positively associated with all dispositions except hedonism, consistent with the OTH framework (Peterson et al. 2005), and with research showing that mindfulness, self-compassion, and gratitude are positively associated with psychological well-being (Voci et al. 2019).

\subsection{The Moderating Effect of Positive Dispositions on Within-Person Variation in Negative and Positive Events}

To test the other hypotheses (H2-H5), we explored how the interactions between each disposition and the intra-individual variation in the frequency and intensity of negative and positive events were associated with time-varying well-being variables. Importantly, the interactions between each dispositions and intra-individual variation in the frequency and in the intensity of events allowed us to investigate the effect of each disposition when events occurred more than usual, and when the recalled self-relevant event was more intense than usual. To avoid multicollinearity problems, we added the interactions for one disposition at a time. Thus, for what concerns the frequency of events, for each of the four dependent variables we re-computed the models in Table 2 by adding two interaction terms, i.e., the interaction between each disposition and within-person variation in the frequency of negative and positive events. We then followed the same strategy for the intensity of the selfrelevant negative and positive event. Coefficients of these interaction terms are reported in Table 4, in Panel A for what concerns the frequency of events, and in Panel B for what concerns the intensity of events. Interactions involving negative events were plotted in Fig. 1, while interactions involving positive events were plotted in Fig. 2.

Results showed that dispositional mindfulness intervened in the positive association between intra-individual variation in negative events and negative affect, both when negative events were more frequent than usual and when the most impactful negative 
Table 4 The interactive effect of positive dispositions and within-person variation in the frequency (Panel A) and intensity (Panel B) of events on well-being

\begin{tabular}{|c|c|c|c|c|c|c|c|c|}
\hline & \multicolumn{2}{|c|}{$\begin{array}{l}\text { Negative } \\
\text { affect }\end{array}$} & \multicolumn{2}{|c|}{ Positive affect } & \multicolumn{2}{|c|}{$\begin{array}{l}\text { Life satisfac- } \\
\text { tion }\end{array}$} & \multicolumn{2}{|c|}{$\begin{array}{l}\text { Meaning in } \\
\text { life }\end{array}$} \\
\hline & $\mathrm{b}$ & $p$ & $\mathrm{~b}$ & $p$ & $\mathrm{~b}$ & $p$ & $\mathrm{~b}$ & $p$ \\
\hline \multicolumn{9}{|l|}{ Panel A } \\
\hline Mindfulness $\times$ W-P frequency of NEs & -0.02 & .038 & 0.00 & .715 & 0.02 & .175 & 0.01 & .474 \\
\hline Mindfulness $\times \mathrm{W}-\mathrm{P}$ frequency of PEs & -0.02 & .193 & -0.00 & .968 & -0.00 & .776 & 0.01 & .571 \\
\hline Self-compassion $\times \mathrm{W}-\mathrm{P}$ frequency of NEs & -0.03 & .132 & -0.02 & .227 & 0.01 & .586 & 0.01 & .652 \\
\hline Self-compassion $\times \mathrm{W}-\mathrm{P}$ frequency of PEs & -0.01 & .716 & -0.05 & .005 & -0.03 & .129 & -0.02 & .375 \\
\hline Gratitude $\times$ W-P frequency of NEs & -0.01 & .550 & -0.00 & .758 & -0.00 & .982 & 0.00 & .849 \\
\hline Gratitude $\times W-P$ frequency of PEs & -0.02 & .304 & -0.02 & .275 & 0.02 & .454 & 0.02 & .259 \\
\hline Hedonism $\times$ W-P frequency of NEs & -0.01 & .768 & -0.02 & .311 & 0.02 & .435 & 0.00 & .952 \\
\hline Hedonism $\times \mathrm{W}-\mathrm{P}$ frequency of PEs & -0.03 & .090 & -0.04 & .026 & -0.03 & .250 & -0.04 & .072 \\
\hline Eudaimonism $\times \mathrm{W}-\mathrm{P}$ frequency of NEs & 0.00 & .978 & -0.00 & .984 & 0.01 & .766 & 0.04 & .054 \\
\hline Eudaimonism $\times \mathrm{W}-\mathrm{P}$ frequency of PEs & 0.01 & .671 & -0.03 & .031 & -0.02 & .226 & 0.01 & .744 \\
\hline \multicolumn{9}{|l|}{ Panel B } \\
\hline Mindfulness $\times$ W-P intensity of the NE & -0.03 & .001 & 0.00 & .861 & 0.01 & .252 & 0.01 & .484 \\
\hline Mindfulness $\times$ W-P intensity of the PE & -0.00 & .729 & 0.01 & .281 & -0.01 & .357 & -0.00 & .703 \\
\hline Self-compassion $\times \mathrm{W}-\mathrm{P}$ intensity of the NE & -0.03 & .036 & -0.00 & .858 & -0.01 & .629 & 0.01 & .334 \\
\hline Self-compassion $\times$ W-P intensity of the PE & 0.02 & .096 & -0.02 & .251 & -0.01 & .603 & 0.02 & .380 \\
\hline Gratitude $\times \mathrm{W}-\mathrm{P}$ intensity of the NE & 0.00 & .763 & -0.01 & .234 & -0.00 & .750 & 0.01 & .459 \\
\hline Gratitude $\times \mathrm{W}-\mathrm{P}$ intensity of the PE & 0.02 & .250 & 0.01 & .625 & 0.01 & .650 & -0.00 & .982 \\
\hline Hedonism $\times$ W-P intensity of the NE & 0.01 & .463 & 0.01 & .544 & 0.01 & .430 & 0.02 & .208 \\
\hline Hedonism $\times \mathrm{W}-\mathrm{P}$ intensity of the $\mathrm{PE}$ & -0.04 & .003 & -0.01 & .526 & 0.02 & .310 & 0.02 & .203 \\
\hline Eudaimonism $\times$ W-P intensity of the NE & 0.01 & .230 & -0.00 & .989 & -0.00 & .937 & 0.03 & .063 \\
\hline Eudaimonism $\times \mathrm{W}-\mathrm{P}$ intensity of the $\mathrm{PE}$ & -0.00 & .905 & -0.01 & .262 & -0.01 & .544 & -0.00 & .754 \\
\hline
\end{tabular}

$W-P$ Within-person, $N E s$ negative events, $P E s$ positive events, $N E$ most impactful negative event, $P E$ most impactful positive event

Results from separate multilevel models (interactions added for one disposition at a time) $p$-values derived with Kenward-Roger approximation, while using REML

event of the preceding four weeks was more intense than usual. The decomposition of these interactions (Bauer and Curran 2005) revealed the buffering, protective role of dispositional mindfulness (H2): intra-individual variation in the frequency of negative events was more strongly associated with negative affect when dispositional mindfulness was low ( $1 S D$ below the mean: $b=0.13, S E=0.02, p<0.001)$ than when mindfulness was high ( $1 \mathrm{SD}$ above the mean: $b=0.09, S E=0.02, p<0.001$ ), and the same pattern emerged for within-person variation in the intensity of the negative event (low mindfulness: $b=0.09, S E=0.01, p<0.001$; high mindfulness: $b=0.04, S E=0.01$, $p=0.004)$.

We found a similar effect, limitedly to intensity of the negative event, also for self-compassion: experiencing a negative event that was more intense than usual was more strongly and positively related to negative affect when self-compassion was low (1 $S D$ below the mean: $b=0.08, S E=0.01, p<0.001)$, than when it was high ( $1 S D$ above the mean: $b=0.05, S E=0.01, p<0.001)$, supporting $\mathrm{H} 3$. 

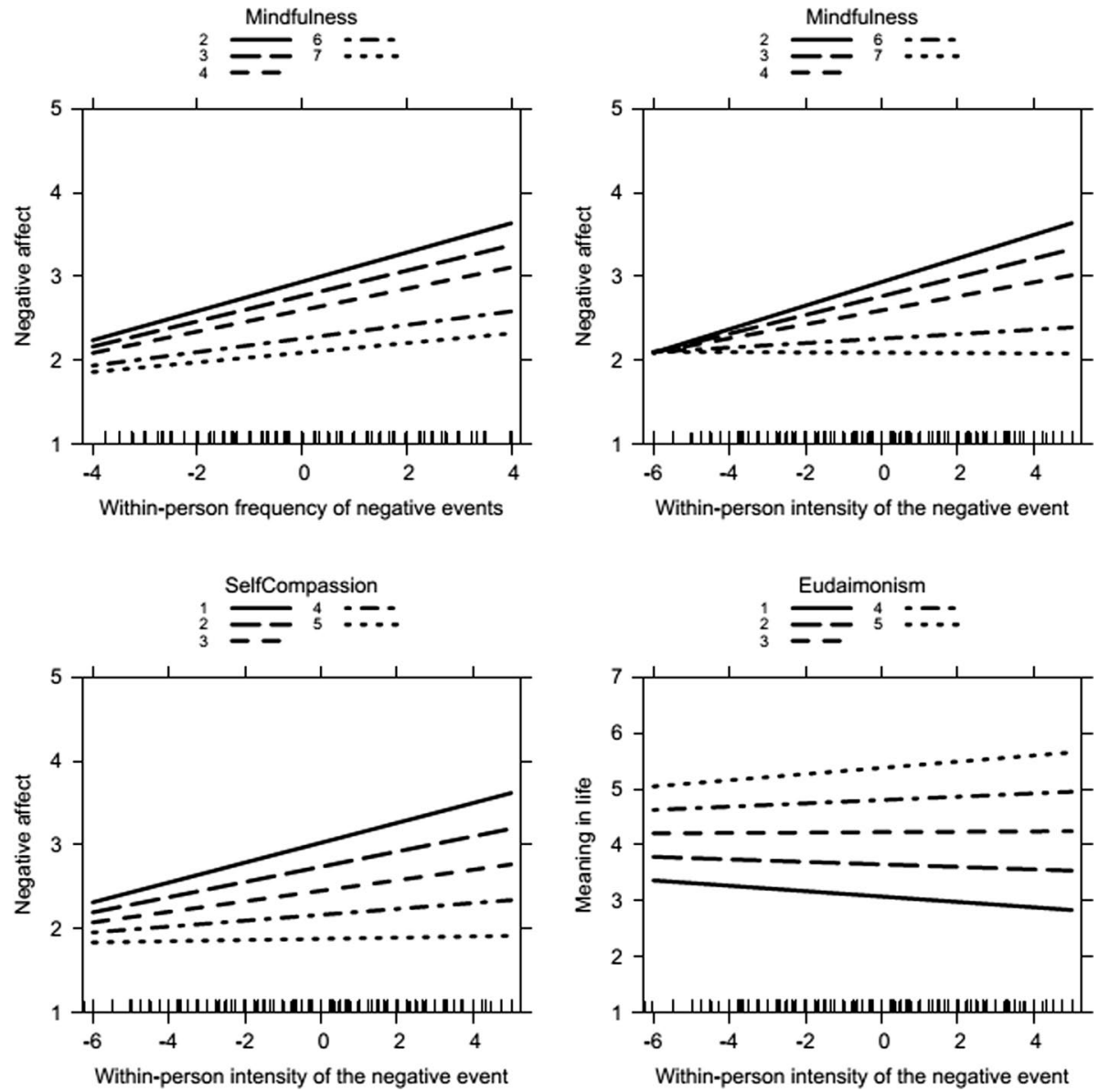

Fig. 1 The interactive effect of individual differences and intra-individual variation in negative events on well-being indicators

The only other moderations involving negative events—even though on the significance threshold-were the ones of eudaimonism, concerning the relationship between withinperson variation in the frequency and intensity of negative events and meaning in life. The decomposition of the interaction with frequency of negative events did not yield statistically significant results, but the one with intra-individual variation in the intensity of the self-relevant negative event did, partially supporting H5: experiencing a negative event that was more intense than usual was associated with higher meaning in life at high levels of eudaimonism ( $1 S D$ above the mean: $b=0.03, S E=0.01, p=0.026$ ), while it was unrelated to meaning at low levels of eudaimonism ( $1 S D$ below the mean: $b=-0.01, S E=0.01$, $p=0.613$ ). This result suggested that eudaimonism may be a disposition enabling growth after intense negative events, consistent with past research on post-traumatic growth (Kashdan and Kane 2011).

On the other hand, several interactions regarding the within-person variation in positive events emerged. First, self-compassion, hedonism, and eudaimonism moderated the association between experiencing more positive events than usual and positive affect. The 

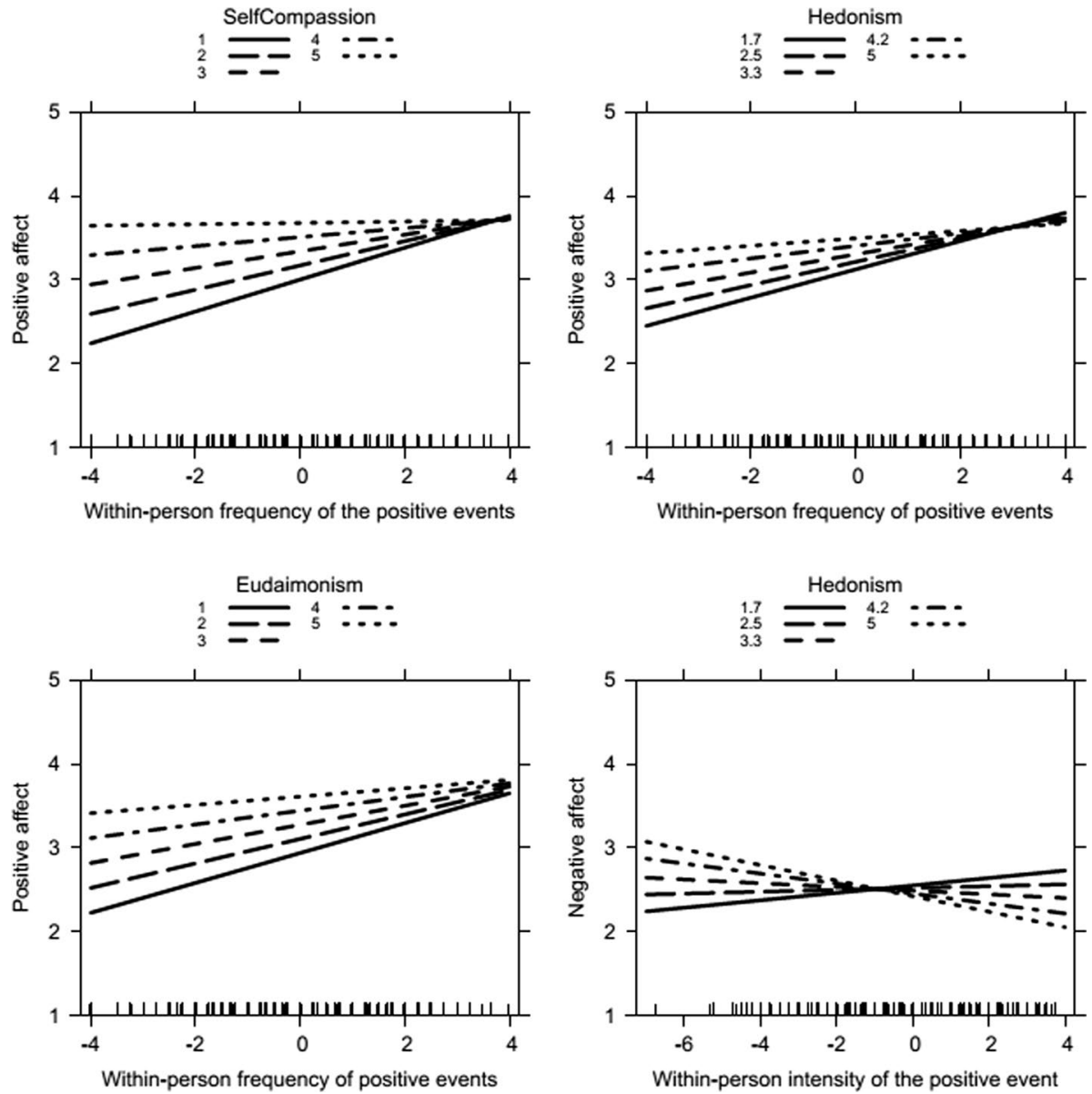

Fig. 2 The interactive effect of individual differences and intra-individual variation in positive events on well-being indicators

decomposition of these effects showed an unexpected, not hypothesized pattern: intra-individual variation in positive events was more strongly associated with positive affect when self-compassion ( $1 S D$ below the mean: $b=0.13, S E=0.02, p<0.001 ; 1 S D$ above the mean: $b=0.07, S E=0.02, p<0.001)$, hedonism ( $1 S D$ below the mean: $b=0.13, S E=0.02$, $p<0.001 ; 1 S D$ above the mean: $b=0.08, S E=0.02, p<0.001$ ), and eudaimonism ( $1 S D$ below the mean: $b=0.13, S E=0.02, p<0.001 ; 1 \mathrm{SD}$ above the mean: $b=0.08, S E=0.02$, $p<0.001)$ were low, than when they were high. This suggests that people scoring lower on these three dispositions need a higher rate of positive events than usual to boost their positive affect; conversely, the positive affect of people scoring higher on self-compassion, hedonism, and eudaimonism is slightly less sensitive to variation in positive events.

Finally, hedonism also moderated the relationship between a more intense positive event and negative affect. Experiencing a self-relevant positive event that was more intense than usual was unrelated to negative affect at low levels of hedonism (1 SD below the mean: $b=0.00, S E=0.01, p=0.954)$, and negatively related to negative affect at high levels of hedonism ( $1 S D$ above the mean: $b=-0.06, S E=0.01, p<0.001$ ), suggesting that 
hedonistic individuals may rely on, and possibly seek, intense positive events to alleviate negative emotions.

\section{Discussion}

In a four-wave longitudinal study, we explored the associations that five individual dispositions contributing to optimal human functioning in different ways-mindfulness, self-compassion, gratitude, hedonism, and eudaimonism - have with time-varying well-being indicators, and with changes in well-being when negative and positive events occur more than usual, or are more intense than usual. Importantly, evidence concerning the role of these five dispositions-which can be developed by specific interventions -in intra-individual well-being dynamics was missing.

Results only partially supported our hypotheses, but also offered new and unexpected insight on how mindfulness, self-compassion, gratitude, hedonism, and eudaimonism are related to reactions to events. Consistent with $\mathrm{H} 1$, mindfulness and self-compassion were negatively associated with time-varying negative affect, while self-compassion, hedonism, and eudaimonism were positively associated with positive affect. Self-compassion, gratitude, and eudaimonism were positively related to life satisfaction and meaning in life, which was also positively associated with mindfulness. These results were obtained controlling for inter- and intra-individual differences in negative and positive events and for the other dispositions; thus, effects of the dispositions have to be interpreted as effects net of the overlaps between mindfulness, self-compassion, gratitude, hedonism, and eudaimonism.

From these results, we can draw three preliminary conclusions: first, self-compassion has a pervasive positive association with well-being, ranging from cognitive to more affective dimensions, characterized by both positive and negative valence. Such pervasiveness can be due to the fact that self-compassion acts on multiple channels: it involves self-kindness (Neff 2003) and positive responses toward the self in times of trouble (Miyagawa et al. 2019), but also the belief that adverse conditions are shared with all humanity (Neff 2003), and it does not involve extreme self-reliance (Choo et al. 2019). These processes reflect both a positive and accepting attitude toward the self, which may be positively related to life satisfaction and positive emotions, and the ability to see negative events in a larger perspective, which can help reduce negative feelings, and find meaning in such events and in life in general.

The second conclusion regards mindfulness: our findings are consistent with previous research showing that mindfulness is more related to negative- than to positive-forms of well-being, such as lower negative affect and reduced psychological symptoms (e.g., Crego et al. 2019), and also to meaning, which is a component of eudaimonic well-being (e.g., Voci et al. 2019). Therefore, data from multiple sources suggest that the tendency to think, feel, and act with an open and receptive awareness (Brown and Ryan 2003) may help people let go of negative feelings, and accept and find purpose in one's own life experiences; however, being mindful does not necessarily imply being happier or more satisfied with life than other people.

Third, hedonism and eudaimonism seem to be more related to positive, than to negative, cognitive and affective processes. This may be explained with the fact that people scoring higher on hedonism and eudaimonism actively search for happiness, either through pleasure and positive sensations, or through serving a higher purpose, and this 
process is likely to bring about positive emotions. This would be consistent with previous research showing hedonism and eudaimonism were more strongly related to positive affect and life satisfaction than to negative affect (Fuochi et al. 2018a, Study 3; Schueller and Seligman 2010), and that they were positively associated with the unfolding of positive emotions when remembering an impactful negative event (Fuochi et al. 2018a). Additionally, eudaimonism-but not hedonism-was also related to the presence of meaning in life, consistent with the search for meaning in everyday activities implied by a eudaimonistic approach to life (Huta and Waterman 2014; Peterson et al. 2005).

As for the other hypotheses, H2, H3, and H5 were partially supported; again, results were obtained controlling for the main effects of the other dispositions. For what concerns $\mathrm{H} 2$, dispositional mindfulness was associated with a lower increase in negative affect when negative events were more frequent than usual, and when the selected selfrelevant event was more intense than usual. These results corroborate the hypothesis that being mindful does not necessarily imply being happier than other people, but perhaps being more resilient to stress and negative events, as found in previous studies (e.g., Brown and Ryan 2003; Dixon and Overall 2016). Dispositional mindfulness may be more strongly related to negative than to positive emotions, while being able to buffer the negative emotional load of negative events, because one of its main mechanisms of action is decentering (e.g., Brown et al. 2015). Decentering is the tendency to step outside one's personal perspective of a lived experience and disengage from the content of one's own thoughts (Bernstein et al. 2015); therefore, mindfulness and decentering involve a quite detached perspective on external situations and inner states, which helps manage negative events and emotions (Brown et al. 2015; Lebois et al. 2015), but it may also hamper the unfolding of strong positive emotions. However, we have to acknowledge the lack of association between dispositional mindfulness and positive affect can be partially due to the set of emotions used: the PANAS mainly involves high-arousal positive emotions, whereas mindfulness may be more associated with low-arousal positive emotions (Chambers et al. 2008).

Self-compassion mitigated the negative association between the intra-individual variation in intensity of the recent self-relevant negative event and negative affect, thereby supporting H3. By definition, self-compassion stands as a useful tool when individuals have to cope with negative events involving self-preoccupation, such as failure, rejection, and embarrassment (Leary et al. 2007; Neff 2003). Indeed, self-compassionate people accept responsibility for their role in unpleasant events without excessively ruminating on these events, thereby mitigating negative affect stemming from them (Leary et al. 2007); in a self-compassionate stance, failures are seen as learning opportunities (Miyagawa et al. 2019).

Although the interaction between intra-individual variation in the intensity of the negative event and eudaimonism was on the threshold of statistical significance in the model for meaning in life, by decomposing it we found that people scoring higher on eudaimonism showed slightly higher meaning in life in adverse conditions, partially supporting H5. This suggests that bad events stimulate growth especially in individuals oriented toward the search for meaning in life, a finding consistent with Viktor Frankl's (1959) hypothesis that searching for meaning can help endure suffering. From our findings, it seems that a focus on meaning and meaningful experiences may help individuals learn from and relate to negative events; this would also be consistent with Kashdan and Kane's (2011) finding that people willing to be in contact with distressing thoughts and feelings related to a trauma report greater posttraumatic growth and meaning, compared to other people with the same level of posttraumatic distress. 
As for interacting effects with positive events, we found an unexpected role of self-compassion, hedonism and eudaimonism: the positive affect of people scoring higher on these three individual differences was stably high, and less boosted by positive events occurring more than usual, as it was for people with lower levels of these dispositions. This finding suggests that self-compassion, hedonism, and eudaimonism help people be happy with their ordinary life, without the need of a multitude of positive events and situations. As these dispositions did not show the same moderating effect on the intensity of the selfrelevant recent positive event, we may hypothesize that people scoring higher on self-compassion, hedonism, and eudaimonism may enjoy and savor positive events, but they might be less sensitive to their quantity.

Moreover, for people scoring higher on hedonism experiencing a positive event that was more intense than usual helped feeling lower negative emotions; this finding suggests that hedonistic individuals may be able to focus on intense pleasurable experiences in a way that mitigates negative affect.

We did not find support for H4: gratitude interacted with neither positive, nor negative events. This suggests that being grateful is positively related to life satisfaction regardless of current life conditions and allows individuals to acknowledge the positive in ordinary life, without enhancing the joy and satisfaction induced by positive events, and without mitigating the negative emotional impact of negative events. Taken together, these results suggest that the five dispositions studied in this paper build well-being through different ways: mindfulness makes individuals less prone to negative affectivity and more resilient to negative shocks; self-compassion is positively associated with multiple dimensions of well-being, buffers negative emotions against intense negative events, and help keep positive emotions less dependent on positive events; gratitude is positively related to a better evaluation of one's life and to higher presence of meaning; hedonism and eudaimonism help keep positive emotions stably high; eudaimonism is also related to higher life satisfaction, as well as being able to turn negative experiences into valuable paths to meaning.

We acknowledge that this study has some limitations: first, we employed a convenience sample, thus results may be not generalizable to the entire Italian population or to other cultural contexts, and should be replicated with a more representative sample. Second, we only relied on self-report data, which may be affected by social desirability responding and other forms of response bias. This second limitation could especially regard the event questions, which did not involve a checklist, but only a personal evaluation: different types of event could have different associations with well-being variables depending on the dispositions - especially orientations to happiness - of the participant. However, personmean centering such event questions and simultaneously including the person means of the variables in the regressions is a useful strategy to model — and thus control for-individual differences in the evaluation of the frequency and intensity of events. Third, collecting longitudinal data was appropriate for our research questions, but longitudinal designs with a larger number of repeated measurements, and with a smaller time interval between them, could add useful evidence to the results of this paper. Fourth, positive and negative events questions were not counterbalanced among respondents, thus we cannot exclude the potential presence of order effects.

Nevertheless, our findings suggest that optimal functioning may be reached through different paths, and that mindfulness, self-compassion, gratitude, hedonism, and eudaimonism carry a set of strategies to overcome negative events, focus on positive emotions, and keep emotional well-being high. However, none of these dispositions seemed to boost the savoring of positive events (Jose et al. 2012), as if they made positive events less necessary to be happy. 
Positive psychology interventions often focus on single dispositions (e.g., gratitude or forgiveness) or activities (e.g., positive writing, goal training), and their effects are evaluated in terms of well-being and reduction of negative psychological symptoms (Sin and Lyubomirsky 2009). From a practical point of view, the results of this paper suggest that future positive psychology interventions could start to consider the importance of events truly occurring to individuals, and could be based on a mix of positive dispositions, teaching individuals how to find the most appropriate way-extracted from that mix - to cope with the situation they are going through. Being able to relate to negative and positive events in manifold and healthy ways may help individuals learn from those events, and flourish through both favorable and adverse conditions.

Funding Open access funding provided by Università degli Studi di Padova within the CRUI-CARE Agreement.

Open Access This article is licensed under a Creative Commons Attribution 4.0 International License, which permits use, sharing, adaptation, distribution and reproduction in any medium or format, as long as you give appropriate credit to the original author(s) and the source, provide a link to the Creative Commons licence, and indicate if changes were made. The images or other third party material in this article are included in the article's Creative Commons licence, unless indicated otherwise in a credit line to the material. If material is not included in the article's Creative Commons licence and your intended use is not permitted by statutory regulation or exceeds the permitted use, you will need to obtain permission directly from the copyright holder. To view a copy of this licence, visit http://creativecommons.org/licenses/by/4.0/.

\section{References}

Bates, D., Maechler, M., Bolker, B., \& Walker, S. (2015). Fitting linear mixed-effects models using lme4. Journal of Statistical Software, 67, 1-48. https://doi.org/10.18637/jss.v067.i01

Bauer, D. J., \& Curran, P. J. (2005). Probing interactions in fixed and multilevel regression: Inferential and graphical techniques. Multivariate Behavioral Research, 40, 373-400. https://doi.org/10.1207/s1532 7906mbr4003_5

Baumeister, R. F., Vohs, K. D., Aaker, J. L., \& Garbinsky, E. N. (2013). Some key differences between a happy life and a meaningful life. The Journal of Positive Psychology, 8, 505-516. https://doi. org/10.1080/17439760.2013.830764

Bernstein, A., Hadash, Y., Lichtash, Y., Tanay, G., Shepherd, K., \& Fresco, D. M. (2015). Decentering and related constructs: A critical review and metacognitive processes model. Perspectives on Psychological Science, 10, 599-617. https://doi.org/10.1177/1745691615594577

Brown, D. B., Bravo, A. J., Roos, C. R., \& Pearson, M. R. (2015). Five facets of mindfulness and psychological symptoms: Evaluating a psychological model of the mechanism of mindfulness. Mindfulness, 6, 1021-1032. https://doi.org/10.1007/s12671-014-0349-4

Brown, K. W., \& Ryan, R. M. (2003). The benefits of being present: Mindfulness and its role in psychological well-being. Journal of Personality and Social Psychology, 84, 822-848. https://doi. org/10.1037/0022-3514.84.4.822

Chambers, R., Lo, B. C. Y., \& Allen, N. B. (2008). The impact of intensive mindfulness training on attentional control, cognitive style, and affect. Cognitive Therapy and Research, 32, 303-322. https://doi. org/10.1007/s10608-007-9119-0

Charles, S. T., Piazza, J. R., Mogle, J., Sliwinski, M. J., \& Almeida, D. M. (2013). The wear and tear of daily stressors on mental health. Psychological Science, 24, 733-741. https://doi.org/10.1177/09567 97612462222

Choo, P. Y., \& Marszalek, J. M. (2019). Self-compassion: A potential shield against extreme self-reliance? Journal of Happiness Studies, 20, 971-994. https://doi.org/10.1007/s10902-018-9978-y

Crego, A., Yela, J. R., Gómez-Martínez, M. Á., \& Karim, A. A. (2019). The contribution of meaningfulness and mindfulness to psychological well-being and mental health: A structural equation model. Journal of Happiness Studies. https://doi.org/10.1007/s10902-019-00201-y 
Davis, P. A., \& Burns, G. L. (1999). Influence of emotional intensity and frequency of positive and negative events on depression. European Journal of Psychological Assessment, 15, 106-116. https://doi. org/10.1027//1015-5759.15.2.106

Diener, E. D., Emmons, R. A., Larsen, R. J., \& Griffin, S. (1985). The satisfaction with life scale. Journal of Personality Assessment, 49(1), 71-75. https://doi.org/10.1207/s15327752jpa4901_13

Dixon, H. C., \& Overall, N. C. (2016). Dispositional mindfulness attenuates the link between daily stress and depressed mood. Journal of Social and Clinical Psychology, 35, 256-269. https://doi.org/10.1521/ jscp.2016.35.3.255

Frank1, V. E. (1959). Man's search for meaning. Boston: Beacon Press.

Fuochi, G., Veneziani, C. A., \& Voci, A. (2018). Differences in the way to conceive happiness relate to different reactions to negative events. Journal of Individual Differences, 39, 27-38. https://doi. org/10.1027/1614-0001/a000246

Fuochi, G., Voci, A., \& Veneziani, C. (2018). Factorial validity and item response theory analysis of the gratitude questionnaire in an Italian sample. TPM Testing Psychometrics, Methodology in Applied Psychology, 25, 313-325. https://doi.org/10.4473/TPM25.3.1

Gander, F., Proyer, R. T., \& Ruch, W. (2016). Positive psychology interventions addressing pleasure, engagement, meaning, positive relationships, and accomplishment increase well-being and ameliorate depressive symptoms: A randomized, placebo-controlled online study. Frontiers in Psychology, 7, 686. https://doi.org/10.3389/fpsyg.2016.00686

Giannopoulos, V. L., \& Vella-Brodrick, D. A. (2011). Effects of positive interventions and orientations to happiness on subjective well-being. The Journal of Positive Psychology, 6, 95-105. https://doi. org/10.1080/17439760.2010.545428

Gurka, M. J. (2006). Selecting the best linear mixed model under REML. American Statistician, 60, 19-26. https://doi.org/10.1198/000313006X90396

Hendriks, T., Schotanus-Dijkstra, M., Hassankhan, A., de Jong, J., \& Bohlmeijer, E. (2019). The efficacy of multi-component positive psychology interventions: A systematic review and meta-analysis of randomized controlled trials. Journal of Happiness Studies. https://doi.org/10.1007/s10902-01900082-1

Hoffman, L., \& Stawski, R. S. (2009). Persons as contexts: Evaluating between-person and withinperson effects in longitudinal analysis. Research in Human Development, 6, 97-120. https://doi. org/10.1080/15427600902911189

Howells, A., Ivtzan, I., \& Eiroa-Orosa, F. J. (2016). Putting the 'app' in happiness: A randomised controlled trial of a smartphone-based mindfulness intervention to enhance wellbeing. Journal of Happiness Studies, 17, 163-185. https://doi.org/10.1007/s10902-014-9589-1

Huta, V., \& Waterman, A. S. (2014). Eudaimonia and its distinction from hedonia: Developing a classification and terminology for understanding conceptual and operational definitions. Journal of Happiness Studies, 15, 1425-1456. https://doi.org/10.1007/s10902-013-9485-0

Ivtzan, I., Young, T., Martman, J., Jeffrey, A., Lomas, T., Hart, R., \& Eiroa-Orosa, F. J. (2016). Integrating mindfulness into positive psychology: A randomised controlled trial of an online positive mindfulness program. Mindfulness, 7, 1396-1407. https://doi.org/10.1007/s12671-016-0581-1

Jose, P. E., Lim, B. T., \& Bryant, F. B. (2012). Does savoring increase happiness? A daily diary study. The Journal of Positive Psychology, 7, 176-187. https://doi.org/10.1080/17439760.2012.671345

Kabat-Zinn, J. (1990). Full catastrophe living: Using the wisdom of your body and mind to face stress, pain, and illness. New York, NY: Delacourt.

Kabat-Zinn, J. (1994). Wherever you go, there you are. New York: Hyperion.

Kashdan, T. B., \& Kane, J. Q. (2011). Post-traumatic distress and the presence of post-traumatic growth and meaning in life: Experiential avoidance as a moderator. Personality and Individual Differences, 50, 84-89. https://doi.org/10.1016/j.paid.2010.08.028

Lambert, N. M., Graham, S. M., Fincham, F. D., \& Stillman, T. F. (2009). A changed perspective: How gratitude can affect sense of coherence through positive reframing. The Journal of Positive Psychology, 4, 461-470. https://doi.org/10.1080/17439760903157182

Leary, M. R., Tate, E. B., Adams, C. E., Batts Allen, A., \& Hancock, J. (2007). Self-compassion and reactions to unpleasant self-relevant events: The implications of treating oneself kindly. Journal of Personality and Social Psychology, 92, 887-904. https://doi.org/10.1037/0022-3514.92.5.887

Lebois, L. A. M., Papies, E. K., Gopinath, K., Cabanban, R., Quigley, K. S., Krishnamurthy, V., et al. (2015). A shift in perspective: Decentering through mindful attention to imagined stressful events. Neuropsychologia, 75, 505-524. https://doi.org/10.1016/j.neuropsychologia.2015.05.030

Lüdecke, D. (2020). sjPlot: Data visualization for statistics in social science. R package version 2.8.2, https://CRAN.R-project.org/package $=$ sjPlot 
Luke, S. G. (2017). Evaluating significance in linear mixed-effects models in R. Behavior Research Methods, 49, 1494-1502. https://doi.org/10.3758/s13428-016-0809-y

Mangelsdorf, J., Eid, M., \& Luhmann, M. (2019). Does growth require suffering? A systematic review and meta-analysis on genuine posttraumatic and postecstatic growth. Psychological Bulletin, 145, 302-338. https://doi.org/10.1037/bul0000173

McCullough, M. E., Emmons, R. A., \& Tsang, J. A. (2002). The grateful disposition: A conceptual and empirical topography. Journal of Personality and Social Psychology, 82, 112-127. https://doi. org/10.1037/0022-3514.82.1.112

Miyagawa, Y., Niiya, Y., \& Taniguchi, J. (2019). When life gives you lemons, make lemonade: Selfcompassion increases adaptive beliefs about failure. Journal of Happiness Studies. https://doi. org/10.1007/s10902-019-00172-0

Neff, K. D. (2003). The development and validation of a scale to measure self-compassion. Self and Identity, 2, 223-250. https://doi.org/10.1080/15298860309027

Neff, K. D., \& Germer, C. K. (2013). A pilot study and randomized controlled trial of the mindful self-compassion program. Journal of Clinical Psychology, 69, 28-44. https://doi.org/10.1002/ jclp. 21923

Nezlek, J. B., Krejtz, I., Rusanowska, M., \& Holas, P. (2019). Within-person relationships among daily gratitude, well-being, stress, and positive experiences. Journal of Happiness Studies, 20, 883-898. https://doi.org/10.1007/s10902-017-9940-4

Peterson, C., Park, N., \& Seligman, M. E. P. (2005). Orientations to happiness and life satisfaction: The full life versus the empty life. Journal of Happiness Studies, 6, 25-41. https://doi.org/10.1007/ s10902-004-1278-z

Piazza, J. R., Charles, S. T., Sliwinski, M. J., Mogle, J., \& Almeida, D. (2013). Affective reactivity to daily stressors and long-term risk of reporting a chronic physical health condition. Annals of Behavioral Medicine, 45, 110-120. https://doi.org/10.1007/s12160-012-9423-0

Ployhart, R. E., \& Vandenberg, R. J. (2010). Longitudinal research: The theory, design, and analysis of change. Journal of Management, 36, 94-120. https://doi.org/10.1177/0149206309352110

R Core Team. (2019). R: A language and environment for statistical computing. R foundation for statistical computing, Vienna, Austria. R version 3.6.2, https://www.R-project.org/

Raes, F., Pommier, E., Neff, K. D., \& Van Gucht, D. (2011). Construction and factorial validation of a short form of the self-compassion scale. Clinical Psychology \& Psychotherapy, 18, 250-255. https ://doi.org/10.1002/cpp.702

Schueller, S. M., \& Seligman, M. E. P. (2010). Pursuit of pleasure, engagement, and meaning: Relationships to subjective and objective measures of well-being. The Journal of Positive Psychology, 5, 253-263. https://doi.org/10.1080/17439761003794130

Shrout, P. E., Stadler, G., Lane, S. P., McClure, M. J., Jackson, G. L., Clavél, F. D., \& Bolger, N. (2018). Initial elevation bias in subjective reports. Proceedings of the National Academy of Sciences, 115, E15-E23. https://doi.org/10.1073/pnas.1712277115

Sin, N. L., \& Lyubomirsky, S. (2009). Enhancing well-being and alleviating depressive symptoms with positive psychology interventions: A practice-friendly meta-analysis. Journal of Clinical Psychology, 65, 467-487. https://doi.org/10.1002/jclp.20593

Smeets, E., Neff, K., Alberts, H., \& Peters, M. (2014). Meeting suffering with kindness: Effects of a brief self-compassion intervention for female college students. Journal of Clinical Psychology, 70, 794-807. https://doi.org/10.1002/jclp.22076

Snijders, T. A. B. (2005). Power and sample size in multilevel linear models. In B. S. Everitt \& D. C. Howell (Eds.), Encyclopedia of statistics in behavioral science (pp. 1570-1573). Chichester, UK: John Wiley.

Steger, M. F., Frazier, P., Oishi, S., \& Kaler, M. (2006). The meaning in life questionnaire: Assessing the presence of and search for meaning in life. Journal of Counseling Psychology, 53, 80-93. https:// doi.org/10.1037/0022-0167.53.1.80

Teasdale, J. D., Segal, Z. V., Williams, J. M. G., Ridgeway, V. A., Soulsby, J. M., \& Lau, M. A. (2000). Prevention of relapse/recurrence in major depression by mindfulness-based cognitive therapy. Journal of consulting and clinical psychology, 68, 615-623. https://doi. org/10.1037/0022-006X.68.4.615

Terracciano, A., McCrae, R. R., \& Costa, P. T. (2003). Factorial and construct validity of the Italian positive and negative affect schedule (PANAS). European Journal of Psychological Assessment, 19, 131-141. https://doi.org/10.1027//1015-5759.19.2.131

Veneziani, C. A., Fuochi, G., \& Voci, A. (2017). Self-compassion as a healthy attitude toward the self: Factorial and construct validity in an Italian sample. Personality and Individual Differences, 119, 60-68. https://doi.org/10.1016/j.paid.2017.06.028 
Veneziani, C. A., \& Voci, A. (2015). The Italian adaptation of the mindful awareness attention scale and its relation with individual differences and quality of life indexes. Mindfulness, 6, 373-381. https:// doi.org/10.1007/s12671-013-0270-2

Voci, A., Veneziani, C. A., \& Fuochi, G. (2019). Relating mindfulness, heartfulness, and psychological well-being: The role of self-compassion and gratitude. Mindfulness, 10, 339-351. https://doi. org/10.1007/s12671-018-0978-0

Wang, L. P., \& Maxwell, S. E. (2015). On disaggregating between-person and within-person effects with longitudinal data using multilevel models. Psychological Methods, 20, 63-83. https://doi. org/10.1037/met0000030

Watson, D., Clark, L. A., \& Tellegen, A. (1988). Development and validation of brief measures of positive and negative affect: The PANAS scales. Journal of Personality and Social Psychology, 54, 1063-1070. https://doi.org/10.1037/0022-3514.54.6.1063

Weinstein, N., Brown, K. W., \& Ryan, R. M. (2009). A multi-method examination of the effects of mindfulness on stress attribution, coping, and emotional well-being. Journal of Research in Personality, 43, 374-385. https://doi.org/10.1016/j.jrp.2008.12.008

Wood, A. M., Froh, J. J., \& Geraghty, A. W. A. (2010). Gratitude and well-being: A review and theoretical integration. Clinical Psychology Review, 30, 890-905. https://doi.org/10.1016/j.cpr.2010.03.005

Zautra, A. J., Affleck, G. G., Tennen, H., Reich, J. W., \& Davis, M. C. (2005). Dynamic approaches to emotions and stress in everyday life: Bolger and Zuckerman reloaded with positive as well as negative affect. Journal of Personality, 73, 1511-1538. https://doi.org/10.1111/j.0022-3506.2005.00357 .X

Publisher's Note Springer Nature remains neutral with regard to jurisdictional claims in published maps and institutional affiliations. 